\title{
TEKNIK PERSUASI BROSUR PROMOSI PENERIMAAN MAHASISWA BARU PERGURUAN TINGGI KEAGAMAAN BUDDHA DI INDONESIA
}

\author{
Suntoro \\ suntoro@stabn-sriwijaya.ac.id
}

Sekolah Tinggi Agama Buddha Negeri Sriwijaya Tangerang

\begin{abstract}
Abstrak
Promosi Penerimaan Mahasiswa Baru (PMB) Perguruan Tinggi Keagamaan Buddha (PTKB) dilakukan dengan cara yang beragam, salah satunya menggunakan brosur. Meskipun cara tersebut sudah mulai ditinggalkan, bagi PTKB brosur masih menjadi primadona. Penelitian ini bertujuan untuk mengetahui teknik persuasif yang ada dalam brosur PMB PTKB Tahun Akademik 2018-2019. Metode penelitian yang digunakan adalah kualitatif analisis isi dengan unit analisis adalah brosur PMB sepuluh PTKB di Indonesia. Teknik pengumpulan data menggunakan dokumentasi, sementara analisis data dilakukan dengan metode padan dengan teknik padan referensial dan teknik pragmatis. Hasil penelitian ini menunjukkan bahwa terdapat lima teknik persuasi yang digunakan dalam brosur PMB PTKB yaitu rasionalisasi, identifikasi, sugesti, konformitas, dan kompensasi, sementara teknik penggantian tidak ditemukan dalam brosur. Oleh karena itu, brosur hendaknya didesain dengan kreatif dan menarik serta memiliki nilai persuasif tinggi agar lebih menarik perhatian.
\end{abstract}

\begin{abstract}
The promotion of new student admission of the Buddhist College is done in various ways, one of which is using brochures. Although this method has already been abandoned, for the Buddhist College, brochure still become the most favorite one. This study aims to find out persuasive techniques contained in the year of 2018-2019 academic brochure. The research method used was qualitative content analysis with the unit of analysis being ten academic brochures Buddhist College in Indonesia. Data collection techniques use documentation, while data analysis is done by matching methods with referential matching techniques and pragmatic techniques. The results of this study indicate that there are five persuasion techniques used in the academic brochure, namely rationalization, identification, suggestion, conformity, and compensation, while replacement techniques are not found in the brochure. Therefore, brochures should be designed creatively and attractively and have high persuasive values to attract more attention
\end{abstract}

\section{PENDAHULUAN}

Pada tahun 2013 secara mengejutkan Philip Kotler mengungkapkan "marketing is dead" dalam salah satu sesi wawancara dengan CEO dan Founder MarkPlus, Hermawan Kartajaya. Ungkapan Bapak Pemasaran Modern tersebut tentu bukan dalam pengertian bahwa pemasaran sudah tidak berguna lagi melainkan lanskap pemasaran modern memang sudah sangat berbeda. Perubahan tersebut tentu tidak terlepas dari perkembangan teknologi informasi dan komunikasi yang memberikan andil besar terhadap pergeseran arus pemasaran.

Lebih lanjut Kotler mengatakan bahwa saat ini dunia usaha, termasuk usaha pendidikan juga harus masuk dalam arus pemasaran baru dan meninggalkan model-model pemasaran lama. Pemasaran lama yang lebih dikenal dengan legacy marketing semakin ompong ditengah himpitan lanskap ekonomi dan marketing yang sudah 
bermetamorfosis. Oleh karena itu, dunia usaha yang tidak mengaplikasikan model pemasaran baru yang sering disebut pemasaran berbasis internet (internet based marketing), besar kemungkinan untuk tergilas laju zaman.

Faktanya masih banyak dunia usaha termasuk usaha pendidikan yang belum menerapkan model pemasaran baru untuk mengoptimalkan animo konsumen, termasuk Perguruan Tinggi Keagamaan Buddha (PTKB). Membengkaknya kuantitas PTKB di Indonesia sekilas seperti sebuah prestasi, tetapi faktanya justru menjadi masalah yang serius. Tercatat dua belas PTKB aktif di Indonesia saat ini dan tersebar di Pulau Jawa dan Sumatera. Oleh karena itu, saling berebut calon mahasiswa (yang kuantitasnya terbatas) sudah menjadi menu setiap tahunnya.

Hingga kini, strategi promosi yang dijalankan masih berkutat model legacy marketing. Model promosi cara lama seperti mulut ke mulut, door to door, dan menyebarkan brosur masih dinilai efektif untuk menjaring calon mahasiswa. Cara terakhir tersebut bisa jadi merupakan rutinitas tahunan yang selalu dilakukan dalam menggaet calon-calon mahasiswa baru meskipun efektivitasnya mungkin jauh dari harapan.

Strategi pemasaran lama yang tetap dilakukan hingga kini bukan tanpa alasan. Beberapa faktor memang menjadi pertimbangan mengapa strategi pemasaran (termasuk membagikan brosur) tersebut masih dianggap efektif untuk merangsang animo masuk PTAB. Pertama, target pasar yang terbatas membuat strategi promosi model lama dianggap lebih efisien. Jumlah lulusan SMA/SMK sederajat yang beragama Buddha setiap tahunnya memang relatif sedikit jika dibandingkan dengan jumlah PTKB yang ada di Indonesia. Kedua, strategi pemasaran modern kurang masuk akal dari segi biaya dan efektivitasnya. Strategi pemasaran modern memang tidak selalu identik dengan biaya yang mahal. Pada situasi tertentu, strategi pemasaran modern juga sarat dengan kemudahan dan efisiensi. Permasalahannya justru terletak pada ketiadaan akses informasi yang memadai pada beberapa daerah yang menjadi lumbung umat Buddha di Indonesia. Ketiga, keberadaan informasi mengenai PTKB masih sangat terbatas sehingga dibutuhkan strategi pemasaran lama dianggap mampu mewadahi kebutuhan tersebut.

Secara praktis, penggunaan brosur sebagai media promosi penerimaan mahasiswa baru di PTAB akan memberi dampak yang optimal jika didesain secara menarik. Brosur dapat memberikan gambaran umum mengenai kondisi PTAB yang tidak banyak diketahui oleh masyarakat Buddhis, khususnya mengenai profil program studi yang ditawarkan. Iklan yang baik dapat dilihat dari beberapa aspek seperti 
struktur, isi, dan bahasa yang digunakan.

Beberapa brosur penerimaan mahasiswa baru yang diedarkan oleh PTKB tak jarang melenceng dari kriteria iklan yang baik. Struktur iklan pada brosur promosi penerimaan mahasiswa baru cenderung menonjolkan sifat informatif daripada persuasifnya. Akibatnya, brosur yang telah dicetak sebagai media promosi masih membutuhkan penjelasan lebih detail mengenai maksud dan tujuan yang sebenarnya. Misalnya, pada brosur penerimaan mahasiswa baru STABN Sriwijaya yang lebih banyak menampilkan profil perguruan tinggi dan prodi yang dimiliki dibandingkan nilai jual prodi ketika masyarakat masuk dalam prodi tersebut. Padahal, pesan persuasif dalam iklan memiliki daya pikat yang lebih hebat dibandingkan pesan informatif dalam konteks menarik minat mahasiswa baru.

Struktur iklan yang baik juga menimbulkan dampak yang luar biasa bagi keberhasilan sebuah iklan. Dalam wacana iklan berbentuk brosur misalnya, proporsi penggunaan tanda berbentuk simbol, gambar, dan bahasa sangat berpengaruh terhadap daya sugestif iklan tersebut. Tak jarang brosur penerimaan mahasiswa baru kurang memperhatikan proporsi tersebut dan terlalu menonjolkan satu tanda saja sehingga menimbulkan kesan yang membosankan.

Isi iklan yang baik harus mencerminkan pesan yang objektif, jujur, tidak menyinggung, dan mampu menarik perhatian. Meskipun demikian tak jarang banyak pengiklan justru "bermain" dalam isi sekadar untuk memberikan nilai persuasif yang lebih dari iklan pada umumnya. Hal tersebut juga terjadi pada brosur penerimaan mahasiswa baru PTAB yang berusaha menarik perhatian masyarakat dengan cara memainkan bahasa. Misalnya ungkapan atau jargon "kuliah gratis", "gratis laptop" dan "beasiswa 100\%". Meskipun informasi yang tertuang dalam brosur tersebut tidak selalu benar (ada pesan tersembunyi dibalik pesan yang tampak), ungkapan-ungkapan tersebut jelas ditujukan untuk menarik simpati sebesar mungkin dari masyarakat. Bahkan dalam kaitannya dengan bisnis pemasaran jasa, cara-cara "hitam" juga sangat mungkin dilakukan. Dalam konteks ini, kita dapat mengetahui bahwa bahasa memainkan peran besar bagi keberhasilan sebuah iklan baik itu iklan yang berbentuk video maupun iklan cetak seperti brosur.

Bahasa iklan hendaknya disampaikan dengan sopan, lugas, dan menarik serta menonjolkan unsur sugestif. Bahasa menjadi modal utama bagi sebuah institusi pendidikan untuk menjual jasa pendidikan yang dimiliki. Bahasa dalam iklan sangat beragam dan menimbulkan implikatur yang menarik. Terkadang untuk memahami maksud sebuah iklan, seseorang harus memahami konteks situasinya. Bahasa dalam brosur 
promosi penerimaan mahasiswa baru memiliki tindak tutur yang beragam seperti menginformasikan, membandingkan, dan menyindir untuk meyakinkan masyarakat terhadap jasa yang ditawarkan.

Meskipun demikian, setiap PTKB pasti memiliki strategi penggunaan bahasa yang berbeda pada brosur sehingga menghasilkan tindak tutur yang berbeda. Demikian juga dengan struktur brosur dan unsur persuasif yang dijual juga pasti berbeda. Dalam penelitian ini peneliti memfokuskan penelitian pada tindak teknik persuasi brosur promosi Penerimaan Mahasiswa Baru (PMB) PTKB di Indonesia. Kajian mengenai teknik persuasif dalam pemasaran jasa pendidikan menjadi sangat menarik karena mengkaji nilai jual, komoditas, bahkan kejujuran PTKB di tengah sulitnya menjaring calon mahasiswa. Oleh karena itu, dalam penelitian ini peneliti mengambil judul "Teknik Persuasi Brosur Promosi Penerimaan Mahasiswa Baru Perguruan Tinggi Keagamaan Buddha di Indonesia”.

\section{KAJIAN TEORI}

\section{Pemasaran Jasa Pendidikan}

Jasa pendidikan memiliki karakteristik yang berbeda dengan usaha jasa jenis lainnya. Pelayanan pendidikan bukan seperti pelayanan dalam bidang lainnya yang menganut prinsip asal barang habis. Menurut Irianto (2010: 211) jasa pendididikan memiliki karakteristik antara lain: (1) lebih bersifat tidak berwujud 304 | Jurnal Kredo Vol. 2 No. 2 April 2019 daripada berwujud; (2) produksi dan konsumsi bersamaan waktunya; dan (3) kurang memiliki standar dan keseragaman. Wijaya (2008: 42) ada empat alasan mengapa pemasaran lembaga pendidikan mutlak diperlukan antara lain: (1) sebagai lembaga nonprofit yang bergerak dalam bidang jasa pendidikan, untuk level apa saja, kita perlu meyakinkan masyarakat dan "pelanggan" (peserta didik, orang tua, serta pihak-pihak terkait lainnya) bahwa lembaga pendidikan yang kita kelola masih tetap eksis; (2) kita perlu meyakinkan masyarakat dan pengguna bahwa layanan jasa pendidikan yang kita kelola relevan dengan kebutuhan mereka; (3) kita perlu melakukan kegiatan pemasaran agar jenis dan macam jasa pendidikan yang kita lakukan dimengerti dan dikenal secara luas oleh masyarakat; dan (4) agar eksistensi lembaga pendidikan yang kita kelola tidak ditinggalkan oleh masyarakat luas. Lebih lanjut Irianto (2010: 213) mengungkapkan ada tiga komponen dasar dalam penerapan pemasaran pendidikan yaitu integrated marketing, create customer satisfaction, dan a profit. Lebih spesifik lagi pemasaran memiliki empat aktivitas yaitu analisis, organisasi, perencanaan, dan kontrol. 
Faktor-Faktor yang Memengaruhi Preferensi Memilih Perguruan Tinggi

Terdapat banyak faktor yang menjadi pertimbangan seseorang dalam menentukan studi lanjut termasuk saat masuk ke perguruan tinggi. Wahab (2011: 5) ada 7 faktor yang memengaruhi preferensi seseorang memilih perguruan tinggi antara lain fasilitas perguruan tinggi, reputasi perguruan tinggi, kualitas pengajaran, prospek kerja, persepsi keluarga, atmosfer kampus, dan pengaruh teman. Mahmudi (2006: 35) ada beberapa faktor yang mempengaruhi preferensi seseorang memilih perguruan tinggi antara lain minat, biaya, status akreditasi, jalur dan jenjang pendidikan, gelar dan sebutan, fasilitas pendidikan, serta kualitas dan kuantitas dosen.

Padmono (2011: 294) ada 7

faktor atau komponen yang mempengaruhi preferensi seseorang memilih perguruan tinggi yaitu harga, produk, layanan, lokasi, keamanan dan kenyamanan fasilitas, serta promosi. Sejalan dengan pendapat Mahmudi dan Padmono, Sawaji, dkk. (2012) juga mengungkapkan beberapa faktor yang menentukan preferensi mahasiswa memilih Perguruan Tinggi antara lain biaya pendidikan, kelompok rujukan, komunikasi pemasaran, citra perguruan tinggi, motivasi, sikap, dan pengambilan keputusan. Berdasarkan beberapa pendapat di atas, dapat disimpulkan bahwa terdapat tujuh faktor yang dijadikani dasar preferensi masyarakat memilih perguruan tinggi. Faktor tersebut yaitu status perguruan tinggi, waktu kuliah, jadwal kuliah, biaya per semester, reputasi perguruan tinggi, jurusan, dan media promosi. Ketujuh faktor tersebut memiliki nilai persuasif yang berbeda antara satu dan yang lainnya. Namun, keberadaan faktorfaktor tersebut saling menunjang satu dan lainnya.

\section{Teknik Persuasi}

Marwoto, dkk. (1987: 176) persuasif merupakan alihan bentuk kata persuation dalam bahasa Inggris yang berarti membujuk atau meyakinkan. Jadi persuasi secara umum adalah ujaran yang berfungsi untuk membujuk atau meyakinkan. Alwi, dkk. (2005: 864) persuasi berarti ajakan kepada seseorang dengan cara memberikan alasan yang meyakinkan, bujukan halus, atau membuktikan pendapat.

Keraf (2003: 124) teknikteknik yang digunakan dalam persuasi meliputi rasionalisasi, identifikasi, sugesti, konformitas, kompensasi, dan subtitusi. Rasionalisasi artinya teknik persuasi dapat dibatasi sebagai suatu proses penggunaan akal untuk memberikan pembenaran kepada suatu persoalan, dasar atau alasan itu tidak merupakan sebab langsung dari masalah itu. Identifikasi artinya persuasi berusaha menghindari situasi konflik dan sikap ragu-ragu, maka penutur harus menganalisa mitra tutur dan seluruh situasi yang dihadapinya dengan seksama. Setelah menganalisa mitra 
tutur dan seluruh situasi, maka penutur dengan mudah dapat mengidentifikasi dirinya dengan mitra tutur (Keraf, 2003: 127).

Sugesti adalah suatu usaha membujuk atau mempengaruhi orang lain untuk menerima suatu keyakinan atau pendirian tanpa memberi suatu dasar kepercayaan yang logis pada orang yang ingin dipengaruhi. Dalam kehidupan sehari-hari sugesti itu biasanya dilakukan dengan kata-kata dan nada suara. Rangkaian katakata yang menarik dan meyakinkan disertai nada suara yang penuh dan berwibawa dapat memungkinkan seseorang mempengaruhi kehadiran yang diajak bicara dengan mudah. Konformitas adalah suatu keinginan atau tindakan untuk membuat diri serupa dengan sesuatu yang lain. Konformitas adalah suatu mekanisme mental untuk menyesuaikan diri atau mencocokan diri dengan sesuatu yang diinginkan itu. Sikap yang diambil pembicara atau penulis untuk menyesuaikan diri dengan keadaan supaya tidak timbul ketegangan adalah juga termasuk juga dalam konformitas. Kompensasi adalah suatu tindakan atau hasil dari usaha untuk mencari suatu pengganti (subtitute) bagi suatu hal yang tidak dapat diterima, atau suatu sikap, atau keadaan yang tidak dapat dipertahankan. Penggantian adalah suatu proses yang berusaha menggantikan suatu maksud atau hal yang mengalami rintangan dan suatu maksud hal lain yang sekaligus juga menggantikan emosi kebencian, asli, atau kadang-kadang emosi cinta kasih yang asli.

\section{METODE PENELITIAN}

$\begin{array}{rcr}\text { Jenis } & \text { penelitian } & \text { yang } \\ \text { digunakan } & \text { adalah } & \text { kualitatif }\end{array}$ deskriptif. Fokus penelitian ini adalah unsur persuasif dalam brosur PMB PTKB tahun akademik 20182019. Unsur persuasif dalam brosur PMB PTKB tahun akademik 20182019 yang menjadi fokus penelitian ini mencakup dua hal yaitu: (1) struktur brosur dan (2) teknik persuasi yang digunakan dalam brosur. Sumber data dalam penelitian ini adalah dokumentasi brosur PMB PTKB tahun akademik 2018-2019. Ada sepuluh brosur yang dijadikan data penelitian ini antara lain brosur PMB Sekolah Tinggi Agama Buddha (STAB) Negeri Sriwijaya Tangerang, STAB Negeri Raden Wijaya Wonogiri, Sekolah Tinggi Ilmu Agama Buddha (STIAB) Nalanda Jakarta, STIAB Smaratungga Boyolali, STAB Syailendra Semarang, STAB Maha Prajna Jakarta, STAB Kertarajaya Malang, STAB Dharma Widya Bandung, STIAB Jinarakkhita Lampung, dan STAB Bodhi Dharma Medan. Brosur yang penulis dokumentasikan ada yang berbentuk cetak dan sebagian berbentuk soft file.

Analisis data dalam penelitian ini menggunakan model Milles\&Hubberman dilakukan dalam 
empat tahap yaitu pengumpulan data, reduksi data, penyajian data, dan penarikan simpulan (Sugiyono, 2009: 91-92). Analisis data dilakukan dengan metode padan dengan teknik padan referensial dan teknik pragmatis. Validitas yang digunakan dalam penelitian ini adalah validitas pragmatik, yaitu untuk melihat seberapa jauh data yang dapat dianalisis sesuai dalam konteks tuturan. Uji realibilitas pada penelitian ini menggunakan uji reliabilitas intrarater, maksudnya adalah dengan membaca dan meneliti objek dengan berulangulang sampai mendapatkan data yang dimaksud. Seperti yang dijelaskan Moleong (2013: 177-180) uji reabilitas ini membutuhkan ketekunan pengamatan penelitinya. Selain itu, juga digunakan realibilitas interater, yaitu mendiskusikan hasil penelitian dengan teman sejawat yang dianggap mempunyai kemampuan intelektual dan kapasitas linguistik yang cukup bagus.

\section{HASIL DAN PEMBAHASAN}

Ada lima teknik persuasi yang digunakan dalam brosur PMB PTKB tahun akademik 2018-2019, yaitu teknik rasionalisasi, identifikasi, sugesti, konformitas, dan kompensasi. Teknik-teknik tersebut dalam brosur PMB telah didukung oleh syarat utama dalam persuasi yaitu watak dan kredibilitas, kemampuan mengendalikan emosi, dan bukti-bukti. a. Teknik rasionalisasi

Rasionalisasi merupakan teknik persuasi dengan cara penggunaan akal untuk memberikan suatu pembenaran kepada suatu persoalan. Kebenaran dalam persuasi bukan kebenaran yang mutlak melainkan sebuah usaha untuk meletakkan dasar-dasar dan melicinkan jalan agar keinginan tercapai. Rasionalisasi dapat berjalan dengan baik apabila institusi mengetahui dengan baik keinginan dan kebutuhan, sikap, dan keyakinan pasar. Bentuk persuasi dengan teknik rasionalisasi yang ditemukan pada brosur adalah penggunaan jargon pada brosur PMB.

Ada tiga jargon PMB yang digunakan oleh PTKB untuk menarik perhatian masyarakat. Jargon dalam brosur tersebut antara lain: (1) maju sukses bersama RW, milik STAB Negeri Raden Wijaya; (2) if it doesn't challenge you, it doesn't change you, milik STAB Bodhi Dharma; dan (3) pendidikan adalah jembatan emas meraih kemajuan dan kesejahteraan, milik STIAB Nalanda. Ungkapan-ungkapan tersebut mengajak pembaca untuk berpikir hingga akhirnya menyetujui dan membenarkan.

Jargon "maju sukses bersama RW" mengajak masyarakat untuk berpikir bahwa jika memiliki keinginian untuk sukses dapat bergabung bersama STAB Negeri Raden Wijaya. Demikian juga dengan ungkapan "if it doesn't challenge you, it doesn't change you" yang dapat dimaknai dengan 
jika tidak ada tantangan maka tidak akan ada perubahan dalam diri. Challenge dalam konteks tersebut merujuk pada kuliah di STAB Bodhi Dharma. Sementara itu, ungkapan "pendidikan adalah jembatan emas meraih kemajuan dan kesejahteraan" adalah pembenaran bahwa untuk meraih kemajuan dan kesejahteraan harus melalui pendidikan. Pendidikan yang dimaksud secara spesifik adalah kuliah di STIAB Nalanda.

b. Teknik identifikasi

Persuasi berusaha menghindari situasi konflik dan sikap ragu, sehingga penutur harus mampu menganalisis mitratutur dan situasi yang dihadapi dengan cara mengidentifikasikan atau menyamakan pelaku persuasi dengan objek persuasi. Agar identifikasi berjalan dengan baik maka harus diciptakan kondisi sesuai harapan pasar.

$\begin{array}{lll}\text { Identifikasi memberi } & \text { peran } \\ \text { penting dalam } & \text { persuasi } & \text { untuk } \\ \text { membentuk citra diri yang sesuai } & \text { sangarat luas. }\end{array}$ Meskipun demikian, hanya ada dua PTKB yang menggunakan identifikasi sebagai teknik persuasinya, yaitu STAB Negeri Sriwijaya dan STAB Syailendra. Bentuk persuasi dengan teknik identifikasi yang ada pada brosur PMB adalah pencantuman slogan kampus.

$\begin{array}{lr}\text { STAB Negeri } & \text { Sriwijaya } \\ \text { mengidentifikan dirinya } & \text { dengan } \\ \text { slogan "Buddhistik } & \text { Unggul } \\ \text { Berkarakter". Slogan } & \text { tersebut } \\ \mathbf{3 0 8} \text { | Jurnal Kredo } & \\ \text { Vol. 2 No. 2 April } 2019 & \end{array}$

bermakna bahwa sivitas akademika STAB Negeri Sriwijaya memiliki pribadi yang berjiwa Buddhis, lebih unggul dalam segala hal, dan memiliki karakter yang baik. Slogan tersebut juga bermakna bahwa jika calon mahasiswa baru mendaftar di STAB Negeri Sriwijaya maka akan memiliki semua karakter yang tertulis dalam brosur tersebut. Sementara itu, STAB Syailendra mengidentifikasikan dirinya dengan slogan "Unggul dalam Moral dan Intelektual". Maknanya sivitas akademika STAB Syailendra memiliki pribadi yang unggul baik dalam perilaku maupun kecerdasan. Profil inilah yang dibentuk ketika mahasiswa melanjutkan studi di STAB Syailendra.

c. Teknik sugesti

Sugesti merupakan usaha membujuk atau memengaruhi orang lain untuk menerima suatu keyakinan tertentu tanpa memberikan dasar kepercayaan yang logis pada orang yang dipengaruhi. Orang yang dipengaruhi dalam konteks ini adalah masyarakat buddhis, lebih spesifik calon mahasiswa baru. Bentuk persuasi dengan teknik sugesti antara lain dosen sesuai bidang, matakuliah sesuai kebutuhan, fasilitas lengkap, pemberian beasiswa, fasilitas asrama gratis, pendaftaran kuliah gratis, kampus tertua, akreditasi, penempatan kerja, lulusan mudah diterima kerja, dan doorprize laptop.

Dosen sesuai bidang dalam konteks brosur PMB merupakan cara persuasi yang digunakan oleh PTKB untuk memberikan pembenaran 
bahwa jika institusi memiliki dosen yang kualifikasinya sesuai maka kualitas pendidikan di perguruan tinggi tersebut juga terjamin. Persuasi tersebut secara tidak langsung memberikan keyakinan kepada pasar bahwa calon mahasiswa baru tidak salah memilih perguruan tinggi tersebut. Terlebih daftar nama dosen ditampilkan pada brosur lengkap beserta gelar akademiknya. Padahal, banyak atribut lain yang turut memengaruhi kualitas pendidikan di perguruan tinggi.

Senada dengan kualifikasi dosen, matakuliah yang sesuai kebutuhan juga memiliki unsur persuasi yang dapat menanamkan sikap serta keyakinan masyarakat dalam memilih perguruan tinggi. Artinya jika sebuah perguruan tinggi memiliki kurikulum yang sesuai dengan kebutuhan pasar maka lulusan dapat dengan mudah terserap di dunia kerja. Namun, faktanya banyak lulusan PTKB yang merasa kesulitan mendapatkan pekerjaan yang sesuai dengan prodi setelah lulus. Bahkan, tak jarang harus menekuni profesi yang sama sekali tidak berhubungan dengan ilmu yang digeluti selama di bangku kuliah. Meskipun demikian, unsur persuasi tersebut sangat menjual karena alasan klasik bahwa sebagian besar orang kuliah untuk mendatkan kerja yang layak.

Teknik persuasi dengan sugesti yang lain adalah dengan mengklaim kelengkapan fasilitas. Padahal, jika ditelusuri tidak lebih dalam semua perguruan tinggi pasti tidak mampu memenuhi semua fasilitas sesuai standar dan keinginan masyarakat. Memang dalam teori pemasaran jasa pendidikan, fasilitas merupakan unsur penting yang dapat memengaruhi preferensi seseorang memilih perguruan tinggi. Perguruan tinggi dengan fasilitas yang cukup lengkap memiliki kecenderungan untuk terpilih lebih banyak daripada yang kekurangan fasilitas. Fasilitas pendidikan memang memberikan andil besar terhadap keberhasilan pendidikan. Oleh karena itu, fasilitas merupakan unsur yang sangat menjual dalam brosur PMB meskipun kebanyakan diletakkan pada bagian amplifikasi.

Di antara jenis sugesti yang tertuang dalam brosur, informasi mengenai beasiswa, asrama gratis, pendaftaran gratis, dan doorprize laptop. merupakan informasi yang memiliki nilai persuasif paling tinggi. Hal ini terkait fakta bahwa rata-rata calon mahasiswa baru PTKB berasal dari kelompok ekonomi keluarga yang kurang baik, sehingga informasi-informasi tersebut sangat menjual. Meskipun dalam faktanya informasi tersebut kadanga tidak $100 \%$ seperti yang tersurat dalam brosur. Ada syaratsyarat tertentu yang harus dipenuhi oleh calon mahasiswa baru untuk mendapatkan fasilitas-fasilitas tersebut.

Sementara itu sugesti status akreditasi, penempatan kerja, lulusan mudah diterima kerja juga memiliki unsur persuasif yang tinggi. 
Meskipun manfaatnya tidak bisa diterima secara langsung namun sugesti tersebut dapat memberikan jaminan kepada calon mahasiswa baru agar mau kuliah di kampus tersebut. Faktanya, sebagian besar orang kuliah memang untuk mendapatkan pekerjaan yang layak.

Status akreditasi jelas memberikan jaminan mutu kualitas sebuah program studi. Paling tidak institusi dan prodi yang telah terakreditasi memiliki reputasi yang jelas dan akan berimbas pada banyak hal seperti pengakuan lulusan. Akreditasi prodi juga sebagai potret bahwa prodi tersebut telah memenuhi standar minimal penyelenggaraan pendidikan yang diterapkan oleh BAN-PT. Oleh karena itu, sugesti penempatan kerja dan lulusan mudah diterima harus dibarengi dengan klaim status akreditasi prodi kampus. Sementara itu, sugesti sebagai kampus tertua tidak memiliki persuasif sehebat kuliah gratis dan jaminan kerja. Kampus tertua lebih merupakan sebuah legitimasi bahwa institusi tersebut telah memiliki pengalaman yang cukup banyak mengelola PTKB. Teknik persuasif dengan sugesti merupakan yang terbanyak di antara teknik persuasi yang lain.

d. Teknik konformitas

Konformitas merupakan suatu tindakan untuk membuat diri serupa dengan sesuatu hal yang lain. Konformitas adalah suatu mekanisme mental untuk mencocokkan diri dengan sesuatu yang diinginkan. Bentuk persuasi

310 | Jurnal Kredo Vol. 2 No. 2 April 2019 dengan teknik konformitas antara lain pelatihan menjadi enterpreneur, kuliah malam hari, dan kuliah hanya dua kali dalam sebulan.

$$
\text { Upaya mencocokan diri }
$$
dengan objek persuasi yang dilakukan institusi dengan mengadakan pelatihan enterpreneur menunjukkan bahwa selain menjadi guru Pendidikan Agama Buddha (PAB), mahasiswa juga sangat berminat pada kewirausahaan. Namun, ketiadaan Prodi Kewirausahaan dan sejenisnya membuat institusi menetapkan enterpreneur sebagai soft skill yang terintegrasi dalam kurikulum Prodi PAB.

Kegiatan pencocokan juga dilakukan oleh STAB Dharma Widya Bandung yang menawarkan kuliah di malam hari dan hanya dua kali dalam sebulan. Pencocokan tersebut dilakukan untuk menjaring mahasiswa yang rata-rata merupakan pekerja yang hanya memiliki waktu belajar di malam hari. Meskipun terlihat kurang masuk akal untuk melakukan perkuliahan hanya dua kali dalam sebulan, namun persuasi tersebut dilakukan untuk menarik perhatian calon mahasiswa baru.

\section{e. Teknik Kompensasi}

Kompensasi merupakan suatu tindakan atau suatu hasil dari usaha untuk mencari pengganti bagi suatu hal yang tidak dapat diterima. Kompensasi dalam iklan ditandai dengan upaya penutur untuk memberikan sesuatu kepada mitratutur dalam kondisi tertentu. 
Teknik kompensasi yang ditemukan dalam penelitian ini antara lain fasilitas bagi calon mahasiswa yang mau menjadi samanera (calon Biksu laki-laki) dan atthasilani (pelaku praktik delapan kemoralan bagi perempuan), makan gratis tiga kali bagi mahasiswa yang tinggal di asrama, dan doorprize laptop bagi calon mahasiswa baru.

Teknik kompensasi dengan menawarkan fasilitas bagi calon mahasiswa yang mau menjadi samanera dan atthasilani dilakukan oleh STAB Kertarajasa. Institusi memberikan kompensasi berupa pendaftaran, biaya kuliah gratis, konsumsi dan keperluar belajar ditanggung oleh yayasan selama kuliah. Hal itu disebabkan oleh selama menjadi samanera dan atthasilani, mahasiswa tersebut harus menjalani sila atau aturan yang ketat dan berbeda dengan umat awam.

Teknik kompensasi juga dilakukan oleh STAB Negeri Raden Wijaya dan STAB Maha Prajna. STAB Negeri Raden Wijaya memberikan kompensasi berupa fasilitas memadai bagi mahasiswa yang tinggal di asrama. Namun, institusi tersebut tidak pernah menyebutkan secara detail fasilitas yang diberikan. Sementara itu, STAB Maha Prajna memberikan kompensasi berupa makan gratis tiga kali sehari bagi mahasiswa yang mau tinggal di asrama. Kompensasi tersebut diberikan karena mahasiswa yang tinggal di asrama harus taat pada aturan yang ketat.
Ada satu teknik persuasi yang tidak ditemukan dalam brosur PMB yaitu penggantian (subtitusi). Penggantian merupakan tindakan atau hasil dari usaha untuk mencari suatu pengganti (subtitute) bagi suatu hal yang tidak dapat diterima. Biasanya, penulis berusaha untuk meyakinkan pembaca untuk mengalihkan suatu objek atau tujuan tertentu kepada objek lain. Dalam brosur PMB teknik ini tidak ditemukan karena secara umum brosur berisi informasi kampus, program studi, fasilitas, dan keunggulan yang dimiliki oleh perguruan tinggi.

\section{SIMPULAN}

Struktur brosur PMB PTKB memiliki struktur kepala, tubuh, dan amplifikasi (perluasan). Bagian kepala brosur berisi tujuan atau maksud utama pembuatan brosur tersebut. Bagian tubuh brosur merupakan penjelas maksud (bagian kepala) yang isinya sangat bervariasi karena setiap PTKB memiliki gaya/model sendiri. Sementara itu, bagian amplifikasi berisi informasi tambahan yang secara umum diisi dengan profil perguruan tinggi. Terdapat lima teknik persuasi yang digunakan dalam brosur PMB PTKB yaitu rasionalisasi, identifikasi, sugesti, konformitas, dan kompensasi. PTKB hendaknya lebih kreatif dan berisi informasi yang persuasif namun tetap mengedepankan nilai-nilai kebenaran dalam mendesain brosur PMB agar menarik perhatian masyarakat. 


\section{DAFTAR PUSTAKA}

Alwi, Hasan, dkk. 2005. Tata Bahasa Buku Indonesia. Edisi ke-3. Jakarta: Balai Pustaka.

Irianto, Yoyon Bahtiar. 2010. Pemasaran Pendidikan: YBI.

Keraf, Gorys. 2003. Argumentasi dan Narasi. Jakarta: PT Gramedia.

Mahmudi, Ali. 2006. Tips Memilih Perguruan Tinggi. Makalah Diseminarkan pada Seminar "Tips Memilih Jurusan, Kembangkan Bakatmu, Tentukan Pilihanmu", Disampaikan di SMA Negeri 3 Klaten, Sabtu, 2 September 2006.

Marwoto dkk. 1987. Komposisi Praktis. Yogyakarta: Hanindita.

Moleong, Lexy J. 2013. Metode Penelitian Kualitatif. Bandung: Remaja Rosdakarya.

Padmono, Yazid Yud. 2011. Analisa Faktor-Faktor yang Mempengaruhi Seseorang Memilih Kuliah D3 di STIE Surabaya. Jurnal Akuntasi, Manajemen Bisnis, dan Sektor Publik (JAMBSP) Vol. 7 No. 3, hlm. 293311.

Sawaji, Jamaludin, Djabir Hamzah, dan Idrus Taba. 2012. Pengambilan Keputusan Mahasiswa dalam Memilih PTS di Sulawesi Selatan. Jurnal STMIK Handayani Makasar.

Sugiyono.2009. Memahami Penelitian Kualitatif. Bandung: Alfabeta.

Wahab, Mohamad Sahrial. 2011. "Preferensi Mahasiswa terhadap Atribut Perguruan Tinggi (Studi Kasus di STIE Perbanas Surabaya)". Skripsi. Surabaya: STIE Perbanas.

Wijaya, David. 2008. Pemasaran Jasa Pendidikan Sebagai Upaya untuk Meningkatkan Daya Saing Sekolah. Jurnal Penabur No.11 Tahun ke-7 Desember 2008. 